\title{
La crítica y la educación médica: hacia un conocimiento liberador. Parte II
}

\author{
Leonardo Viniegra-Velázquez* \\ Unidad de Investigación en Medicina Basada en Evidencias, Hospital Infantil de México Federico Gómez, Ciudad de México, México
}

\section{Resumen}

La crítica del quehacer médico como espacio educativo implicó caracterizar el entramado de lógicas, ideas y prácticas prevalentes: la disyunción y el reduccionismo; el binomio salud-enfermedad; la historia natural de la enfermedad; la medicalización de la vida social; la tecnologización deshumanizante de la práctica médica, y la medicina supresora reduccionista. La crítica continúa discutiendo la contribución de ese entramado al control social como agente de la dominación de los intereses de lucro sin límites y como expresión del poder de la industria de la salud, justificándose con la argumentación de alternativas tendientes a superar ese entramado: la lógica transdisciplinaria y el concepto de organismo como totalidad jerarquizada e interactuante con su entorno respecto de la disyunción y el reduccionismo; la historia cultural de la enfermedad como alternativa a la historia natural de la enfermedad y al binomio salud-enfermedad; el bien vivir, la búsqueda de la superación espiritual, intelectual, moral y convivencial que confiere sentido profundo a la vida humana, como alternativa a la medicalización y antídoto de la tecnologización deshumanizante y los rasgos degradantes; la medicina estimulante de fuerzas curativas endógenas para afecciones crónicas no trasmisibles, cuyo fundamento de factibilidad y credibilidad radica en la omnipresencia del efecto placebo con respecto a la medicina supresora, basada en fármacos con efectos secundarios indefectibles. Sin una educación basada en la crítica, difícilmente el conocimiento liberador podrá acompañar y orientar a médicos y otros profesionales a organizarse en la búsqueda, desde su ámbito, de un mundo inclusivo, igualitario, justo, solidario y cuidadoso del ecosistema planetario.

Palabras clave: Reduccionismo. Medicalización. Medicina supresora. Medicina estimulante. Efecto placebo.

\section{Critique and medical education: towards liberating knowledge. Part II}

\begin{abstract}
The critique of medicine begins at unveiling and specifying its network of predominant logics, ideas and practices: logics of disjunction and reductionism; the health-disease binomial; the natural history of the disease; the medicalization of social life; the dehumanizing technologization of medical practice and reductionist suppressive medicine. It goes on to argue about its role as agents of domination of limitless profit interests and as an expression of the power of the health industry, justifying itself with the proposal of alternatives tending to overcome that network: transdisciplinarity and the concept of organism as hierarchical totality and interacting with its environment, with respect to disjunction and reductionism; the cultural history of the disease in relation to the health-disease binomial and the dehumanizing technologization; good living, the search for
\end{abstract}

Correspondencia:

*Leonardo Viniegra-Velázquez

E-mail: leonardo.viniegra@gmail.com
Disponible en internet: 18-03-2019 Bol Med Hosp Infant Mex. 2019;76:55-65

www.bmhim.com

1665-1146/@ 2019. Hospital Infantil de México Federico Gómez, impreso por Permanyer México SA de CV, todos los derechos reservados. 
spiritual, intellectual, moral and coexistence growth as meaning of human life, as an alternative to the medicalization and antidote of degrading traits and stimulating medicine of the endogenous healing forces of the organism whose foundation of possibility and credibility is the placebo effect as an alternative to suppressive therapy for non-communicable chronic conditions, based on the pharmacological effect with unfailing side effects. It concludes that without an education based on critique, liberating knowledge would hardly accompany and guide the various social groups in the search for an inclusive, pluralistic, egalitarian, fair, solidary and caring of the planetary ecosystem world.

Key words: Reductionism. Medicalization. Suppressive medicine. Stimulating medicine. Placebo effect.

\section{Introducción}

\section{La crítica y la medicina}

La crítica de algunas facetas de la medicina identifica y caracteriza las lógicas, ideas y prácticas predominantes en este vasto ámbito (saberes ortodoxos y convencionales, usos y costumbres) que, al formar parte del currículo médico como supuestos implícitos y verdades explícitas interiorizadas por el alumnado, convierte a los profesionales en reproductores sociales de tales saberes que operan, al igual que en otros espacios, como agentes de la dominación de los intereses de lucro sin límites al afianzarlos, favorecerlos o encubrirlos.

\section{Las lógicas subyacentes}

Las lógicas subyacentes -que escapan a la conciencia porque no son objeto de reflexión por quienes actúan bajo su influencia- operan como reglas implícitas del bien pensar y actuar, rigen y depuran desde las sombras y por largos periodos el tipo de ideas y prácticas que alcanzan el predominio en este campo:

- La lógica de la disyunción ${ }^{1}$, patente en la idea de enfermedad como objeto independiente o autónomo (teoría nosológica), en la separación entre congénito y adquirido o genético y ambiental y en la escisión de quehaceres otrora integrados que configura una división del trabajo médico y científico en especialización progresiva: aparición incesante de especialidades, subespecialidades, disciplinas y subdisciplinas que se autonomizan. La disyunción impide a los «damnificados" captar totalidades e interdependencias entre los quehaceres donde están inmersos, distanciándolos de una visión integradora que haga inteligible el mundo que pisan, insensibles a la quiebra civilizatoria son permisivos - por acción u omisión- con la dominación de los intereses de lucro sin límites.

- La lógica reduccionista ${ }^{1}$ ostensible en la pretensión de explicar e interpretar cada enfermedad en sí misma («la historia natural de la enfermedad»), sin considerar quién la padece $y$, menos aún, de sus circunstancias y condiciones de vida. También en la equiparación del organismo sano con una «máquina perfecta» y del enfermo con una "averiada»: se trataría de identificar sus mecanismos alterados para poder actuar sobre él a fin de restablecer el funcionamiento adecuado. Este mecanicismo es raíz de la especialización excluyente del quehacer médico, un rasgo degradante que lo desvirtúa, donde el especialista privilegia en su actividad un fragmento o función del organismo y centra sus esfuerzos en repararlo o regresarlo al patrón de normalidad, aunque tal propósito pueda significar un perjuicio para otro fragmento o función, para el organismo en su conjunto o para la vida de relación del paciente. La máquina como metáfora es una pobre cognición de la vida, aun de la menos compleja, ya que pierde de vista, entre otras cualidades vitales, que cada organismo es único (no una máquina con rendimiento promedio); que el proceso vital es la interacción perpetua del organismo con su entorno y es cambio incesante generador de novedades a cada momento (desarrollo y maduración). Esto se deja de lado en los montajes experimentales: se provocan efectos para registrar conjuntos de observaciones (no individualidades), se buscan asociaciones unidireccionales de corta duración en situaciones controladas en el interior de ambientes simplificados y estandarizados (causalidad mecanicista). La idea de máquina en la mente y las expectativas de los médicos subyace a muchos fracasos de la atención atribuibles a pacientes que «osan no comportarse maquinalmente»: desobediencia, indisciplina, veleidad, inconsistencia o rebeldía.

En la investigación biomédica, el reduccionismo físico-químico subyace al tipo de problemas planteados, a las hipótesis, al diseño del experimento, al tipo de sucesos relevantes a observar y a la interpretación de los hallazgos. El predominio de esta investigación obedece a sus mayores facilidades para financiarse y difundir sus resultados, que se deben -ioh sorpresa!- a su sintonía con los intereses dominantes en dos sentidos: consumidora obligada de «tecnología de punta» 
imprescindible para un quehacer de "vanguardia» y tener acceso a revistas de alto impacto, que contribuye al jugoso negocio, y lo más importante, sus resultados son el insumo por excelencia de las innovaciones tecnológicas, punta de lanza de la competitividad de las megaempresas y de la consecución de altas tasas de ganancia. La profusión de innovaciones configura y reconfigura una práctica médica cada vez más fragmentada, impersonal y dependiente de la tecnología que se designa tecnologización deshumanizante, donde tanto profesionales como pacientes idealizan la tecnología ${ }^{2}$ y subestiman la clínica. Así, el especialista se va convirtiendo en mero operador de «tecnologías inteligentes» y en prescriptor maquinal de "los mejores fármacos» según la moda en turno.

El predominio abrumador del reduccionismo mecanicista y físico-químico en las ciencias de la vida se revela en la convicción generalizada de que indagar en el microcosmos físico-químico es lo realmente científico; lo demás son débiles remedos cuando no ilusiones o fantasías. También en la creencia de que la explicación última del proceso vital y las enfermedades radica en ese microcosmos molecular, ignorando el orden biológico y confundiendo descripción con explicación. La descripción exhaustiva del movimiento vital en términos físico-químicos -caracterizar infinidad de compuestos, reacciones, secuencias, redes y mecanismos para reconstruir patrones, pautas y funciones-, además de ser un objetivo inalcanzable ante un microcosmos infinito, cambiante y cognitivamente inagotable para fines prácticos, no puede explicar lo que es propio del orden biológico: la permanencia, estabilidad y cambio perpetuo (crecimiento, desarrollo, maduración y envejecimiento) de una totalidad de insondable complejidad, en virtud de los procesos de integración y regulación de infinidad de funciones, complejos de comportamientos, ciclos y ritmos que obedecen a las formas de interacción del organismo con los objetos significativos de su medioambiente moduladas por su momento etario.

\section{Las ideas explícitas y las prácticas predominantes}

En cuanto a las ideas y prácticas predominantes en este campo y en este tiempo, que se manifiestan entreveradas, lo primero a destacar es lo siguiente:

- El binomio salud-enfermedad que rige la organización, la operación y las estrategias de las instituciones de salud a escala planetaria y tiende a valorizar la vida humana y sus vicisitudes por la presencia o ausencia de enfermedad. Aunque la idea de salud según la Organización Mundial de la Salud es el completo bienestar físico, mental y social, su obvia ajenidad a la condición humana, su desmesura y vaguedad hicieron prevalecer «la no enfermedad», que oscureció y suplantó el significado de una vida digna, grata, estimulante o serena. No obstante, las instituciones y la avasallante publicidad han convertido su preservación o recuperación en el imperativo vital que conforma, progresivamente, la forma de ser y de vivir de la gente. Tal presión social ocasiona, por un lado, una «obsesión enfermiza" por la salud y, por el otro, una fobia a las enfermedades, que generan un mercado creciente de consumidores compulsivos de «lo bueno para recuperar o preservar la salud", que sostiene la boyante y poderosa industria y explica el predominio indisputado y excluyente de este binomio en la apreciación de la vida humana que obedece a su sintonía con los intereses dominantes de lucro sin límites.

- La medicalización de la vida humana. En los ambientes sociales descritos, la población es cada vez más dependiente de los servicios sanitarios y va introduciendo la «racionalidad médica» (alerta y sospecha perenne de las enfermedades y lucha implacable) en sus modos de vida como centro de sus preocupaciones y de sus responsabilidades vitales: es la medicalización de la forma de vivir ${ }^{3}$. La medicalización como expresión de la predominancia del binomio salud-enfermedad no es una consecuencia obligada de la asimilación de las verdades científicas a la vida cotidiana, sino una situación histórica configurada por la industria (en todas sus variantes) que tiene como razón de ser, muy por encima de cualquier otra consideración, la obtención de altas tasas de ganancia que logra al manipular el mercado con publicidad incesante e intimidante que inocula a las inermes víctimas (incluidos los que prestan los servicios) con altas dosis de fantasías engañosas, seguridades ilusorias $\sin$ sustento, temores inducidos, necesidades creadas y alienantes o expectativas infundadas. Progresivamente, las vicisitudes de la vida diaria, que en otros tiempos se afrontaban como peripecias menores, ahora se convierten en «problemas de salud» que acrecientan el mercado de consumidores y desvían la atención de los solicitantes de ayuda de los procesos sociales que subyacen a la presencia creciente y precoz de las enfermedades (crónicas) somáticas y psíquicas: condiciones y circunstancias cada vez más adversas para formas de vida digna, estimulante, productiva, 
gratificante, serena y fraternal. En otras palabras, la medicalización opera como uno de los mecanismos de control de conciencias más efectivo que ensimisma a las personas y las torna indiferentes, insensibles o cómplices involuntarias de la degradación. Aquí, la sintonía con los intereses dominantes es múltiple: los afianza porque la medicalización es condición de la prosperidad de la industria, los favorece al propiciar el consumismo compulsivo y los encubre al controlar mentes y cuerpos.

- La idea de progreso social como desarrollo tecnológico incesante en atmósferas configuradas por los rasgos degradantes propicia el fetichismo de la tecnología ${ }^{2}$, raíz de la tecnologización deshumanizante de la vida actual y de la práctica médica en particular, la cara más actual de la degradación y forma más encubierta del control de conciencias y cuerpos al servicio de la dominación de los intereses de lucro. De igual manera, la idea de que a mayor investigación y desarrollo tecnológico mayor progreso en el cuidado de la salud es discutible, ilusoria y engañosa, porque los investigadores, presos del reduccionismo físico-químico y sometidos a los intereses de la industria de la salud e inmersos en la medicalización, reducen sus aportes a insumo de las innovaciones tecnológicas conminados por el financiamiento selectivo de proyectos según los intereses de la industria (son cada vez más proyectos por encargo), lo que condiciona las prioridades de investigación que se establecen, el tipo de problemas que se plantean, las formas de indagarlos y la tecnología utilizada en su realización. En tales situaciones, la libertad de investigación es un señuelo, el potencial crítico y creativo de esta labor se desvanece y la búsqueda del conocimiento es suplantada progresivamente por la del financiamiento. Con escasas excepciones, se financian investigaciones de problemas de salud (reales o creaciones de la medicalización) que prometan alta rentabilidad por el mercado potencial de consumidores inducidos. Se dejan de lado los no promisorios para los negocios que aquejan a mayorías precarias, así se trate de los más acuciantes, prevalentes, de alta incidencia, de mayor morbilidad 0 de tratamientos accesibles, no invasivos o de mayor beneficio potencial. De ahí el reproche: «iqué ciencia es esta, que permanece indiferente, acomodaticia, aquiescente o cómplice de la dominancia de los intereses de lucro sin límites, que hunden la civilización y devastan el planeta!»

\section{Algunas lógicas, ideas y prácticas alternativas}

Después de caracterizar lo relevante de las lógicas, ideas y prácticas predominantes y argumentar las razones de su predominio, enseguida se recapitulan y actualizan ensayos sobre diversos asuntos, desarrollados en las dos últimas décadas que implican lógicas, ideas y prácticas alternativas en su pretensión de superar lo establecido.

- Lógica transdisciplinaria. Como alternativa al reduccionismo mecanicista, la lógica transdisciplinaria está implícita en la teoría del organismo como totalidad compleja -la complejidad inherente a la vida- que supone procesos de integración y regulación sistémicos que inciden a todos los niveles de la organización vital: molecular, subcelular, celular, tisular, orgánico. Obedecen a las anticipaciones de las situaciones de interacción con los objetos significativos de su medioambiente hacia la consumación de las actividades vitales básicas: preservación de la integridad y la vitalidad, alimentación, reproducción y convivencia con los iguales -formas culturales- en el transcurso de las diferentes fases de la ontogenia: crecimiento, desarrollo, maduración, envejecimiento ${ }^{4}$.

Esta visión holística de la ontogenia inspirada en la teoría Gaia ${ }^{a}$ supondría para la medicina un descentramiento nosológico que favorece la especialización incluyente (inversa a la excluyente y a la disyunción) que relativiza sus labores en un contexto amplio de interdependencias y pondera decisiones y recomendaciones en función de esa totalidad ${ }^{5}$. También favorecería la medicina humanística porque su referente no es la enfermedad, sino el paciente en sus circunstancias. En el ámbito científico, tal enfoque permitiría trascender el reduccionismo físico-químico como única verdad científica y propiciar un viraje en el tipo de problemas que se plantean, en la forma de

a La teoría Gaia de James Lovelock, resultado de sus acuciosas y dilatadas investigaciones, plantea argumentos incuestionables para explicar qué es la vida y por qué prosperó en nuestro planeta: «...excepto cuando la vida se hace cargo de su planeta y lo ocupa de manera extensiva, no se cumplen las condiciones necesarias para su persistencia. La vida planetaria tiene que ser capaz de regular su clima y estado químico. Periodos parciales, ocupación incompleta o visitas ocasionales no son suficientes para vencer las fuerzas ineludibles que gobiernan la química y física de un planeta»; este pasaje interpretado dentro del marco discursivo y conceptual de la teoría de la ontogenia podría expresarse así: la característica más distintiva de la vida en su conjunto a escala planetaria es la anticipación de sí misma al crear y reproducir las condiciones de su permanencia y evolución. 
abordarlos y, sobre todo, en la interpretación y valoración de los hallazgos.

- La historia cultural de la enfermedad ${ }^{6}$, alternativa a la idea de enfermedad predominante, es una perspectiva holística de entendimiento de la enfermedad (crónica) que devela lo ilusorio del dogma vigente: la historia natural de la enfermedad ${ }^{7}$, porque en la explicación de condición humana, la cultura ha relevado y subordinado a la natura. Desde el alba, los humanos afrontaron la presencia indefectible de malestares de cierta magnitud y permanencia que implicaban sufrimientos corporales o psíquicos, limitaciones diversas para realizar tareas, inconvenientes varios para la convivencia o muerte prematura. Surgió, así, la distinción entre sucesos que significaban 0 anunciaban malestares 0 sufrimientos y los favorables o propios de una vida común: los primeros se consideraron, en lo esencial, diferentes a los segundos y, por tanto, como extraños al organismo que nuestros ancestros aprendieron a reconocer, valorar, contrarrestar, aminorar o sobrellevar según sus mitos, tradiciones y posibilidades. Históricamente, las diversas culturas configuraron ambientes propicios para ciertas enfermedades, crearon sus modos de entenderlas, de percibirlas y reconocerlas, de actuar sobre ellas, de sobrellevarlas y de morir. En virtud de la cultura -no de la natura- el «paisaje nosológico» se ha ido transformando a lo largo del tiempo: erradicación, disminución, persistencia, reaparición o exacerbación, según las regiones, de males infecciosos y carenciales; incremento vertiginoso de la prevalencia y precocidad de las enfermedades crónico-degenerativas; emergencia incesante de nuevas afecciones infecciosas y laborales; recrudecimiento alarmante de enfermedades iatrogénicas, diversificación e intensificación de las adicciones o multiplicidad creciente de «errores congénitos del metabolismo" que sobreviven.

Según la historia cultural de la enfermedad, las enfermedades crónicas no son objetos independientes 0 extraños al organismo, sino «variaciones peculiares y diferenciadas de las formas de ser de los humanos que, por su carácter desfavorable, son motivo de acciones sui generis por la cultura de pertenencia con propósitos de evitarlas, suprimirlas, mitigarlas o impedir sus efectos más perjudiciales». De aquí deriva otra idea de paciente: «individualidad que, por su herencia biológica y cultural, la multiplicidad de ambientes de los que ha formado parte y las contingencias del día a día, ha llegado a cierta forma de ser que le ocasiona sufrimientos, malestares, inconvenientes 0 limitaciones que requiere de apoyo, comprensión, ayuda y acciones confortantes". Bajo el marco intelectivo e interpretativo de la historia cultural de la enfermedad, médicos y pacientes podrían concienciar los ambientes «insalubres y patogénicos» que subyacen a la «pandemia» de enfermedades crónicas y su trasfondo: el orden injusto que aniquila los anhelos de libertad y justicia de los pueblos; arrasa los valores propios de convivencias respetuosas, solidarias, cooperativas y fraternas (el imperio de los rasgos degradantes), y devasta el ecosistema planetario. Tal perspectiva podría contribuir a un renacimiento del humanismo, al distanciarse del reduccionismo mecanicista y revalorar el papel de la relación médico-paciente al debilitar la medicalización y el tecnofetichismo que la sostiene, al «humanizar» la tecnologización y favorecer proyectos vitales empeñados en la búsqueda del bien vivir y un replanteamiento de la problemática de investigación en salud y sus prioridades. Como expresión de ese renacimiento, adquiriría prioridad en el quehacer médico favorecer, en los enfermos crónicos, la búsqueda de autonomía y dignificación recurriendo, entre otras alternativas, a exhortaciones existenciales, como la siguiente ${ }^{6}$ : "La enfermedad es una forma de ser que no podemos elegir ni eludir; suele ser adversa a nuestros anhelos, aspiraciones y proyectos entrañables; debemos entenderla, asumirla, sobreponernos y aprender a vivir serenamente; solo así nos acompañará a ser mejores, más dignos, comprensivos y solidarios.”

- El bien vivir. Con respecto a la idea salud -ausencia de enfermedad-, cuya preservación se instaló como imperativo vital y es núcleo de la medicalización de la vida, una alternativa humanizadora en este ámbito es el concepto de bien vivir ${ }^{8}$, con antecedentes en una tradición del deber ser de toda «persona respetable» integrado por dos componentes: la posesión y uso, con mesura, de los bienes necesarios y suficientes para un diario vivir con satisfacción y bienestar, y el cuidado y preservación de la vida al actuar con diligencia, honradez, moderación y sensatez. Estas ideas sustanciosas de corte individualista ameritan un replanteamiento basándose en la prioridad de otros valores e imperativos en estos tiempos oscuros, un carácter colectivo en la búsqueda de un mundo hospitalario: proyectos vitales altruistas que luchan por la dignificación de la vida humana y planetaria (la dignidad, principal damnificado de la degradación y base del progreso humano) ${ }^{9}$ como centro de convergencia de iniciativas surgidas en los diversos espacios del trabajo social que, como fuerzas multicéntricas, 
emprendan desde distintos frentes la búsqueda del progreso genuino y la edificación paulatina de un mundo propicio a la superación espiritual, intelectual, moral y convivencial de la condición humana (lo material, única cara reconocible del progreso en estos tiempos de obsesión por el consumo, suele ser un obstáculo al progreso así entendido), donde el cuidado de la salud como obsesión vital polarizante adquiriría otra fisonomía y un sentido diferente bajo otras prioridades: acompañante propicio a formas de vida digna, serena, fraternal y responsable de cuidar el ecosistema planetario.

- Medicina supresora (MS) y medicina estimulante (ME). En lo que se refiere a la crítica de la práctica terapéutica -trasciende la superficie de los acontecimientos más allá de especificar y corregir la «mala práctica» o prevenir daños colaterales- se destaca uno de sus rasgos más prominentes respecto a la pretensión-aspiración de las acciones de eliminar o destruir el objeto extraño y autónomo (la enfermedad) mediante un arsenal siempre creciente de antiinflamatorios, antihipertensivos, antirreumáticos, inmunosupresores, antialérgicos, antineoplásicos, ansiolíticos 0 antidepresivos. Es la MS, donde las innovaciones tecnológicas (los nuevos fármacos), como cristalización del reduccionismo físico-químico, producen sus efectos al suprimir ciertas moléculas o reacciones químicas consideradas origen-causa de la enfermedad en cuestión ${ }^{9}$. La MS es predominante en occidente, a pesar de sus exorbitantes costos, fracasos innumerables y efectos colaterales indefectibles al grado de motivar el desarrollo de la prevención cuaternaria ${ }^{10,11}$, porque representa lo más lucrativo de la «industria de la salud» (sintonía con los intereses dominantes). Esta industria, a la par que impone y promociona la MS bajo el eslogan de «encarnación de la ciencia», desacredita y excluye (por "anticientíficas") otras formas de tratamiento como las medicinas alternativas (MA).

En las MA ancestrales, la enfermedad se entiende como una especie de disarmonía sistémica que buscan restablecer al estimular -no suprimir- las fuerzas curativas endógenas, de cuya existencia el efecto placebo es evidencia inequívoca. De ahí el considerarlas como variantes de la $\mathrm{ME}^{9}$. Las $\mathrm{MA}$, al recurrir a tecnologías tradicionales de bajo costo y favorecer en los pacientes más autonomía, menor dependencia y vulnerabilidad a la medicalización, y cierta renuencia al consumismo de remedios, representan un estorbo al «gran negocio de la salud» y la razón de fondo de su descalificación y exclusión ${ }^{b}$. Así, la crítica permitió develar caracteres diferenciales contrastantes de la terapéutica actual-que permanecían en las sombras o confundidos- en su aparente homogeneidad: supresor y estimulante, una caracterización no exenta de simplificación y esquematismo. Para precisar las diferencias entre la MS y la ME, los argumentos más fuertes derivan de contrastar el efecto farmacológico (EF) propio de la MS y el efecto placebo (EP) que fundamenta la posibilidad de la ME.

El EF se origina en el microcosmos físico-químico al modificar reacciones y moléculas a las que se atribuye una contribución causal significativa de la afección a tratar. Esta idea causal, aunada a la del tratamiento efectivo con químicos (fármacos), ejemplifica el pensamiento reduccionista que afirma que un sistema complejo solamente puede explicarse por reducción a sus partes fundamentales (simples) ${ }^{12}$. La diana de un fármaco, al interior de una inconmensurable complejidad integrada y jerarquizada de lo macro psicosocial a lo micro físico-químico, es un elemento infinitesimal que forma parte y es configurado por una secuencia de reacciones. A su vez, es eslabón de cadenas integradas en redes en el interior de mecanismos intrincados, que se articulan y acoplan dentro de caminos metabólicos y funcionales bajo los imperativos de la regulación y la integración orgánicas, preservando el carácter sistémico, cíclico y rítmico del proceso vital de un organismo en interacción incesante con los objetos significativos de su entorno. La introducción de una sustancia ajena y reactiva en tal concierto vital, buscando el EF, provoca una «discordancia" con el fluir regulatorio e integrador, cuya dirección es de lo macro a lo micro, manifiesta en la necesidad de repetir indefinidamente el fármaco (afección crónica), en reacciones secundarias indefectibles, en reactivaciones o exacerbaciones frecuentes que obligan a modificar tratamientos con nuevos efectos secundarios, a agregar más supresores cerrando el círculo vicioso, que para la industria es «virtuoso».

El carácter estimulante de ciertas estrategias terapéuticas, que podría parecer fantasioso, ilusorio o carente de sentido a los fieles de la ortodoxia, tiene un fundamento empírico inequívoco en la omnipresencia del EP en situaciones curativas de todo tipo

b Se aclara que el carácter estimulante de las MA no es garantía de que logren invariablemente sus propósitos ni que sean inmunes a la charlatanería y al fraude, sinos de nuestro tiempo. 
(esto incluye, por supuesto, los tratamientos a base de fármacos) ${ }^{c}$. EI EP alude a la mejoría de síntomas, signos o malestares, o la modificación favorable de indicadores de laboratorio alterados del paciente no atribuibles a una intervención terapéutica deliberada, que es resultado de una movilización sistémica del organismo inducida por autosugestión, derivada de la confianza de mejoría depositada en ciertos objetos que resultan significativos del ambiente curativo: un médico afectuoso, una pastilla roja, una inyección poderosa, una imagen venerada o un lugar de culto, casi siempre por vivencias favorables precedentes ${ }^{13}$. El EP, revelador de la existencia de fuerzas curativas endógenas ${ }^{\mathrm{d}}$, cuya movilización de lo macro (sistémico) a lo micro (físico-químico) anticipa lo esperado, está presente en una gran diversidad de situaciones curativas a condición de que la búsqueda y expectativa de alivio sea intensa. Esta omnipresencia del EP que resulta de la movilización de fuerzas curativas endógenas (de asombrosa selectividad), cuya dirección de lo macro psicosocial a lo micro físico-químico, justifica reconocerlo y plantearlo como una «variante fisiológica» no reconocida que acompaña a los flujos regulatorios e integradores incesantes del organismo -que se actualiza bajo circunstancias peculiares- inducida por la confianza de alivio y guiada, con exquisita selectividad, por la localización, intensidad y características de las molestias percibidas, que se adelanta a lo esperado y se manifiesta en mejoría de multiplicidad de trastornos (el interés por indagar el EP ha ido declinando, de ahí que las referencias no sean recientes) $)^{14-20}$. A primera

c Un craso error de la investigación científica que solo repara en los hechos no en las ideas es confundir el EP con "cosa placebo». La creencia de que comparar un fármaco con una sustancia inerte permite separar el EF del EP pierde de vista que en cualquier "situación curativa» puede estar presente el EP y que, en muchos casos, los beneficios atribuidos a un medicamento se deben más al EP -incitado en el proceso terapéutico- que al farmacológico. Por otra parte, el llamado efecto nocebo -inverso al EP-, que alude al empeoramiento de síntomas, signos o molestias del paciente por la sugestión/ expectativa de efectos negativos de una terapia por vivencias previas, no corresponde a un efecto secundario atribuible a un fármaco, por lo que cabe especular sobre su participación -como agregado a los efectos indeseables- en resultados pobres o contraproducentes de ciertas formas de terapia supresora (quimioterapia).

d Esto explicaría por qué el EF -inverso al EP- puede exacerbar las molestias (consecuencias contraproducentes) al debilitar u oponerse a las fuerzas curativas endógenas, o decaer al "contender» con tales fuerzas lo que exige incrementar la dosis (acrecentando el riesgo de aparición de nuevos o más graves efectos secundarios) o cambiar a fármacos de «mayor potencia». vista, parecería que el EP es una reproducción fiel del EF o viceversa, al provocar cambios físico-químicos análogos. Sin embargo, existe una diferencia radical: el EP obedece a un patrón de movilización sistémica que nace en lo psicosocial y sigue trayectos a través de diferentes niveles descendentes de complejidad y provoca «reacomodos concordantes» relativamente estables (que explican la ausencia de efectos secundarios) entre ciclos y ritmos sistémicos, complejos de comportamientos, pautas funcionales, caminos metabólicos, mecanismos, redes y cadenas de reacciones que anticipan lo esperado, la mejoría de las molestias con una especificidad asombrosa. Concienciar tal universalidad del EP que confiere credibilidad al carácter estimulante de algunas MA puede abrir mentes a nuevos espacios de reflexión, de entendimiento y, sobre todo, de indagación del quehacer social más influyente en la vida de las sociedades actuales que deriven, en su caso, en la conveniencia, y aun en la necesidad de incorporar la ME como alternativa prometedora para afecciones crónicas. Para un tratamiento más amplio y pormenorizado se remite al lector, en obvio de espacio, a otras fuentes ${ }^{9,21}$.

\section{Epílogo}

La crítica, entendida como lógica de pensamiento metódico del proceso de cognición que pone todo en cuestión, duda de lo "comprobado y definitivo", va a la raíz de lo considerado "natural y evidente» y propone formas de pensar y actuar que buscan superar lo establecido respecto a los objetos cognitivos en cuestión. Además, subyace a la construcción de este ensayo que, de inicio, procedió a retomar el diagnóstico de la situación histórica actual ${ }^{3}$ y de las condiciones y circunstancias sociales que la hicieron posible, mismas que se sintetizan, para recapitular, en forma de supuestos, acompañados de una tesis explicativa, que constituyeron el marco interpretativo, valorativo y argumentativo de este trabajo sobre la crítica de la educación médica:

- Los dos supuestos vinculados: primero, el mundo asolado por una degradación omnímoda evidencia el agotamiento y ruina de una civilización basada en el lucro sin límites, que convierte en mercancía lo más sublime y vil de la condición humana, y en rentable las peores atrocidades y la devastación planetaria, comprometiendo como nunca la viabilidad de nuestra especie. Segundo, el colapso civilizatorio, como punto de llegada de un proceso de 
decadencia paulatina, no puede entenderse sin la insensibilidad de sociedades con el mayor nivel histórico de escolaridad y la escasa o insuficiente resistencia de las diversas organizaciones sociales (a lo largo y ancho del planeta) que reaccionan a la adversidad dispersas, desvinculadas o confundidas, o permanecen indiferentes, permisivas o cómplices de la degradación.

- La tesis: explicar por qué la dominancia de los intereses de lucro ha arrasado sin encontrar mayores cortapisas a su poder destructivo precisa reconocer la enorme eficacia del control de conciencias y cuerpos por el sistema de dominación que opera a través de tres aparatos «no violentos»:

- El mediático: los medios masivos tradicionales y los cibernéticos; y el del espectáculo (en especial los deportes), cuyo blanco es la manipulación de afectividades al incitar filias, fobias, convicciones, odios, simpatías, conformismo, fatalismo o temores y al persuadir, desinformar o «fabricar realidades»; al ocultar, encubrir y volver invisible la degradación; al espiar, confundir, embaucar o alienar; al desfogar emociones hacia la catarsis y la evasión «despresurizando" la indignación, el descontento, la protesta o la rebeldía contra un sistema desigual, injusto, excluyente y deshumanizado que recurre a las peores atrocidades (despojo, guerras de todo tipo, terror, eliminación) para mantener su dominación.

- El escolar: a todos los niveles, vía la educación pasiva (prevalente) que perpetúa los rasgos degradantes, como el individualismo, la pasividad (ante los abusos del poder de toda índole), la competitividad, el consumismo (real o imaginario), la especialización excluyente y la vulnerabilidad a la manipulación, que son condición sine qua non de la dominación, y reproduce las ideas y prácticas predominantes en la multiplicidad de espacios del quehacer social.

- El laboral: en todas sus variantes, en virtud de que cada espacio está regido por ciertas ideas y prácticas cuyo predominio obedece a su sintonía, directa 0 indirecta, con los intereses dominantes de lucro sin límites que, al escapar a la conciencia («son la realidad misma») o considerarse la encarnación indiscutible del progreso en el campo respectivo, operan, quizá, como el más eficaz -y menos reconocido- «dispositivo» de control social.

Bajo este marco interpretativo y valorativo, la crítica de la educación médica precisó considerar diferencialmente dos objetos, el educativo y el laboral, para captar las particularidades en sus formas de operar el control de conciencias y cuerpos. El primero, por la vía de perpetuar los rasgos degradantes y la reproducción social de las ideas y prácticas prevalentes en cada espacio de trabajo; el segundo, por la introyección de los usos y costumbres (ideas y prácticas predominantes) que configuran cada espacio especializado y excluyente donde imperan los rasgos degradantes. De ahí la presentación por separado de lo propio de cada ámbito procurando no disociarlos.

\section{La educación}

En lo que se refiere a la crítica de la educación pasiva (imperante también en la medicina), profundizarla requirió, como mínimo, vislumbres de ideas y prácticas alternativas contrastantes como condición para poder caracterizarla. Es decir, contar al menos con esbozos de una teoría de la educación participativa resultó necesario para esa crítica al revelar, por contraste, aspectos relevantes y pormenores que hubiesen pasado inadvertidos o permanecido en silencio, y viceversa.

El núcleo de la educación pasiva está representado por la idea de conocimiento equiparable a un aprendizaje memorístico, acumulativo y efímero de información heterónoma, desprovista de sentido y por la pedagogía implícita centrada en facilitar el consumo y asimilación dogmática de las verdades establecidas que, a su vez, favorecen una lectura de comprensión irreflexiva y acrítica como forma de relación prominente de los estudiantes con los contenidos del currículo. Esto explica su contribución decisiva -involuntaria- a la persistencia de los rasgos degradantes que impregnan las atmósferas sociales ya que, lejos de criticarlos y desalentarlos, propicia su perpetuación.

La teoría de la educación participativa, una construcción alternativa a la educación pasiva resultado de la crítica de esta, sostiene, contrastando cada aspecto citado, que el conocimiento es elaboración y reelaboración propia de los educandos con la mediación imprescindible de la crítica, que construyen y reconstruyen versiones propias de sí mismos y su contexto. La pedagogía implícita se condensa en contagiar entusiasmo por entender quiénes somos y dónde estamos, y procurar ambientes propicios para la crítica y la elaboración del conocimiento. El acto de estudiar responde a una búsqueda entusiasta por entender, a través de la crítica, asuntos con sentido para la experiencia vital que lleva a concienciar, enjuiciar y proponer, con infinidad de variantes y matices, respecto a 
lo bien o mal planteado, lo interesante o insulso, lo esclarecedor o confuso, lo fuerte o débil, o externar coincidencias, discrepancias o propuestas de superación. El derrotero participativo supone un conocimiento progresivamente penetrante y liberador, principal antídoto contra los rasgos degradantes y una necesidad imperiosa en estos tiempos -si se aspira a revertir la degradación, que es condición para legar un mundo hospitalario a las generaciones por venir- que implica una concienciación perspicaz del mundo humano y, a la larga, un poder de autogestión colectiva capaz de conformar fuerzas sociales multicéntricas y convergentes cuyo horizonte, lejano pero no indiscernible, son sociedades participativas, inclusivas, igualitarias, justas, solidarias y cuidadosas del ecosistema planetario, en búsqueda perenne de la superación espiritual, intelectual, moral y convivencial de la condición humana.

\section{La medicina}

Para la crítica propositiva de las ideas y prácticas predominantes de la labor médica iniciada décadas atrás ${ }^{22}$, se recapitularon los diferentes tópicos desarrollados y se agruparon de acuerdo a los aspectos prominentes de la crítica.

- Develar las lógicas organizadoras del pensamiento y la acción: la disyunción y el reduccionismo mecanicista y físico-químico. Especificar ideas y prácticas predominantes en este campo: la especialización excluyente como forma actual de la división del trabajo en el mundo moderno; la polaridad salud-enfermedad y la historia natural de la enfermedad que rigen las estrategias del cuidado de la salud de las instituciones respectivas y, en el plano de la experiencia, en virtud de la idea de progreso que prevalece, la medicalización de la vida humana que polariza las formas de vivir tanto de los profesionales como de los pacientes y la tecnologización deshumanizante que desvirtúa la esencia del quehacer médico.

- Proponer y argumentar alternativas tendientes a superar lo establecido respecto a los objetos de cognición:

El concepto de organismo, sustentado en el reconocimiento del orden biológico y el cultural bajo una perspectiva transdisciplinaria integradora de los seres vivos incluidos los humanos, como alternativa a la disyunción, al reduccionismo mecanicista físico-químico y a la especialización excluyente.

La historia cultural de la enfermedad, una mirada transdisciplinaria donde las enfermedades (particularmente las crónicas) son variantes de las formas de ser de las personas; como alternativa que pone de relieve las limitaciones de la historia natural de la enfermedad y de la idea de enfermedad.

El concepto del bien vivir pone el acento en la recuperación del sentido de la vida que ha ocupado a las grandes filosofías: la superación espiritual, intelectual, moral y convivencial de lo humano en su aspiración a formas de vida digna, serena, cooperativa, fraterna, solidaria y responsable del cuidado del ecosistema planetario, que lleva implícito el emprendimiento de proyectos vitales colectivos y altruistas empeñados en la dignificación de la vida en todas sus manifestaciones. Este concepto es la alternativa al de salud y a la medicalización que polariza la energía vital en el cuidado de la propia salud y en la lucha contra la enfermedad, y desvía la atención de la degradación que es el telón de fondo de malestares y aflicciones rampantes, también representa un derrotero vital divergente al del imperio de los rasgos degradantese.

Al profundizar en la crítica del espacio terapéutico de las diversas estrategias médicas occidentales y orientales, se esclareció una diferencia cualitativa entre los mecanismos de acción de los remedios utilizados que, al contrastarlos, permitió clarificar, por un lado, la índole supresora -de moléculas y reacciones químicas- de los fármacos empleados en el tratamiento de las enfermedades, en especial las crónicas no trasmisibles, que se acompañan indefectiblemente de efectos secundarios. Por otro lado, el carácter estimulante, ejemplificado por el efecto placebo omnipresente en toda situación curativa y por buena parte de las medicinas alternativas ancestrales que, a pesar de ser objeto de descrédito, descalificación o exclusión por obstaculizar el "gran negocio de la salud", entrañan potencialidades dignas de investigación y de aprovechamiento en beneficio de los dolientes.

e Cabe destacar el papel relevante que han tenido las contrastaciones (entre lo predominante y lo alternativo o entre oposiciones y divergencias) en la construcción de este ensayo, en las posibilidades de la crítica, en los alcances y la fuerza de las argumentaciones y, en consecuencia, como material insustituible de profundización de la crítica en la procuración de ambientes propicios para ejercerla y para elaborar un conocimiento progresivamente penetrante, como parte del proceso de formación de otro tipo de médicos comprometidos por un mundo mejor. Nada más lejano de un aprendizaje carente de sentido, basado en el consumo y acumulación de las verdades establecidas a manera de información heterónoma, fragmentaria, inconexa, asimilada dogmáticamente, propio de la educación pasiva. 
Este ensayo subraya que la crítica de la educación médica implica cuestionar obligadamente tanto los saberes ortodoxos y convencionales de lo propiamente educativo como del ejercicio de la medicina. La crítica profunda y creativa como lógica de pensamiento metódico fue el hilo conductor de la construcción de este trabajo. Así, lo primero se relaciona con su carácter profundo: la pretensión de desentrañar la trama de lógicas, ideas y prácticas imperantes en cada dimensión considerada y develar su forma de operar como "agentes de la dominación" de los intereses de lucro sin límite, que han colapsado la civilización y devastado el ecosistema planetario. Lo segundo tiene que ver con el aspecto creativo: desarrollar alternativas tendientes a la superación de lo que se da por sentado respecto a los objetos de conocimiento en cuestión.

A manera de síntesis de este trabajo, cabe complementar el epígrafe de la primera parte: "La docencia realmente fecunda principia cuando "contagia entusiasmo" por entender quiénes somos y dónde estamos»; agregando: "...y prosigue al procurar ambientes cada vez más propicios para la crítica profunda y creativa, y la elaboración de un conocimiento penetrante y liberador.»

Sin un viraje epistemológico de la educación prevalente hacia la educación participativa que oriente los esfuerzos de los protagonistas hacia la promoción y ejercicio efectivos de la crítica en su connotación profunda y creativa, muy difícilmente el conocimiento penetrante y liberador surgirá y podrá acompañar a las sociedades actuales -hoy arrastradas a la degradación y condenadas a habitar un mundo inhóspito y devastado- para dar cumplimiento al deber supremo e indeclinable trasmitido de generación en generación (que se ha desdibujado en estos tiempos aciagos donde imperan los atributos degradantes, hasta el grado de la indiferencia e insensibilidad con tal responsabilidad): el legado de un mundo hospitalario a las futuras generaciones que pasa, forzosamente, por la preservación y el cuidado del ecosistema.

Si bien cada cual tiene o debería de tener su versión del acontecer que marca nuestro tiempo, aclaro que al plantear la situación actual como agotamiento y ruina civilizatoria no se trata de alarmismo o de dramatizar, sino de concienciar y entender un momento histórico de extrema gravedad que a todos atañe, inédito por la degradación espiritual, intelectual, moral y convivencial sin precedentes; por la anulación de los anhelos de libertad, igualdad, justicia y autodeterminación de los pueblos; por la retirada y «reclusión» de los valores propios de relaciones sociales respetuosas, fraternas y solidarias; por la devastación planetaria que no se detiene; por la rentabilidad de los etnocidios y ecocidios; por la absoluta prioridad de los buenos negocios sobre la vida (en sus muy diversas manifestaciones) que provoca la contaminación omnímoda del aire, los mares, los ríos, los lagos, los suelos, las plantas, los animales, nuestros alimentos y nuestros cuerpos; por la aniquilación de poblaciones «redundantes» e insumisas por medio de guerras (de todo tipo) y terror; por la migración forzada de millones por violencia, despojo o pobreza hacia «la nada»; por la biodiversidad tan diezmada por causas humanas: la devastación planetaria con casi todas las especies silvestres aún existentes amenazadas, en riesgo, en peligro, en vías o en extinción inminente; por el colapso climático ya irreversible ${ }^{23}$ que representa la imposibilidad material, más temprano que tarde, de oportunidades futuras de vida digna para la mayoría de la población humana ${ }^{24}$ y de condiciones favorables para una biodiversidad robusta -la fuerza vital de Gaia-, lo cual niegan, minimizan u ocultan las megaempresas extractivas y prosiguen con sus acciones destructivas y contaminantes, muy rentables.

Se concluye con una paráfrasis del pensamiento de Boaventura de Sousa Santos que alude a otra variante del control de conciencias y cuerpos por el sistema de dominación que abona a su eficacia: "En el mundo que nos toca vivir, las perversidades se transforman, por su recurrencia, en normalidades."

\section{Conflicto de intereses}

El autor declara no tener ningún conflicto de intereses.

\section{Financiamiento}

No se recibió financiamiento para este trabajo.

\section{Bibliografía}

1. Morin E. El pensamiento subyacente. El método IV. Las ideas. Madrid: Cátedra; 1998. p. 222-33.

2. Viniegra-Velázquez L. El fetichismo de la tecnología. Rev Invest Clin. 2000;52:569-80.

3. Viniegra-Velázquez L. El bien vivir: ¿cuidado de la salud o proyecto vital? Parte I. Bol Med Hosp Infant Mex. 2016;73:139-46.

4. Viniegra-Velázquez L. Anticipación y ontogenia. Penetrando el proceso vital: más allá de la adaptación, el azar y la selección natural. Teoría de la interiorización del entorno y la anticipación. México: Ed. del autor; 2012. p. 341-64.

5. Lovelock J. Las edades de Gaia. Una biografía de nuestro planeta vivo. Barcelona: Tusquets; 2000. p. 54-55.

6. Viniegra-Velázquez L. La historia cultural de la enfermedad. Rev Invest Clin. 2008;60: 527-44.

7. Leavell HR, Clark EG. Preventive medicine for the doctor in his community. An epidemiologic approach. New York: McGraw Hill; 1953.

8. Viniegra-Velázquez L. El bien vivir: ¿cuidado de la salud o proyecto vital? Parte II. Bol Med Hosp Infant Mex. 2016;73:283-90. 
9. Viniegra-Velázquez L. Medicina supresora y medicina estimulante: una mirada penetrante de la práctica médica. Bol Med Hosp Infant Mex. Publicación pendiente.

10. Martínez González C, Riaño Galán I, Sánchez Jacob M. Prevención cuaternaria. La contención como imperativo ético. An Pediatr (Barc) 2014;81:396.e1-e8.

11. Gérvas J, Pérez Fernández $M$. Uso y abuso del poder médico para definir enfermedad y factor de riesgo, en relación con la prevención cuaternaria en España. Gac Sanit. 2006;20:127-34.

12. Honderich T, editor. Reductionism. The Oxford Companion of Philosophy. New York: Oxford University Press; 2005. p.793-5.

13. Viniegra Velázquez L. El efecto placebo. Su dimensión teórica y sus implicaciones prácticas. Ciencia. 1987;38:131-46.

14. De Maria A, Craven DE, Heffernan JJ, McIntosh TK, Grindlinger GA McCabe WR. Naloxone versus placebo in treatment of septic shock. Lancet. 1985;325:1363-5.

15. Beecher HK. Pain in men wounded in battle. Ann Surg. 1946;123:96-104

16. Beecher HK. Measurement of subjective responses. Quantitative effects of drugs. New York: Oxford University Press; 1959.
17. Porter JM, Culter BS, Lee BY, Reich T, Reichle FA, Scogin JT, et al. Pentoxifylline efficacy in the treatment of intermittent claudication multicenter controlled double blind trial with objective assessment of chronic occlusive arterial disease patients. Am Heart J. 1982:104:66-74.

18. Morison RA, Woodmansey A, Young AJ. Placebo responses in arthritis trial. Ann Rheum Dis. 1961;20:179-84.

19. Amsterdam EA, Wolfson S, Gorlin R. New aspects of placebo response in angina pectoris. Am J Cardiol. 1969;20:249-54.

20. Molling PA, Lockner AW, Sauls RJ, Eisenberg L. Committed delinquent boys: the impact of perphenazine and of placebo. Arch Gen Psychiatry. 1962;7:70-4.

21. Goldberg B, compilador. Medicina alternativa. La guía definitiva. California: Future Med Publish Inc; 1999. p. 37-48.

22. Viniegra-Velázquez L. ¿Qué significa la resolución de un problema clínico? Rev Invest Clin. 1981;33:151-9.

23. Lovelock J. La venganza de la tierra. La teoría Gaia y el futuro de la humanidad. Barcelona: Planeta; 2007.

24. Lovelock J. La tierra se agota. El último aviso para salvar nuestro planeta. Barcelona: Planeta; 2011. 